\title{
A historical recount of chordoma
}

\author{
Ronald Sahyouni, MS, ${ }^{1}$ Khodayar Goshtasbi, BS, ${ }^{1}$ Amin Mahmoodi, BS, ${ }^{2}$ and \\ Jefferson W. Chen, MD, PhD',2
}

${ }^{1}$ School of Medicine and ${ }^{2}$ Division of Neurotrauma, Department of Neurological Surgery, University of California, Irvine, California

\begin{abstract}
Chordoma, a rare bone tumor that occurs along the spine, has led scientists on a fascinating journey of discoveries. In this historical vignette, the authors track these discoveries in diagnosis and treatment, noting events and clinicians that played pivotal roles in our current understanding of chordoma. The study of chordoma begins in 1846 when Rudolf Virchow first observed its occurrence on a dorsum sellae; he coined the term "chordomata" 11 years later. The chordoma's origin was greatly disputed by members of the scientific community. Eventually, Müller's notochord hypothesis was accepted 36 years after its proposal. Chordomas were considered benign and slow growing until the early 1900s, when reported autopsy cases drew attention to their possible malignant nature. Between 1864 and 1919, the first-ever symptomatic descriptions of various forms of chordoma were reported, with the subsequent characterization of chordoma histology and the establishment of classification criteria shortly thereafter. The authors discuss the critical historical steps in diagnosis and treatment, as well as pioneering operations and treatment modalities, noting the physicians and cases responsible for advancing our understanding of chordoma.
\end{abstract}

https://thejns.org/doi/abs/10.3171/2017.7.SPINE17668

KEY WORDS chordoma; historical vignette; neurosurgery; spine; tumor; oncology

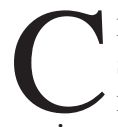

HORDOMA is a rare tumor that occurs in bones of the skull (mainly of clival origin), the centrum of the mobile spine, and the bones in the sacrococcygeal region. Chordoma has an age-adjusted incidence of 8 cases per million persons per year, as calculated by McMaster et al. using the Surveillance, Epidemiology, and End Results (SEER) program of the National Cancer Institute for the period from 1973 to $1995 .{ }^{37}$ Furthermore, it accounts for approximately $1 \%-4 \%$ of all bone malignancies. ${ }^{17,53}$ These highly recurrent low-grade neoplasms can affect patients of all age groups; however, they most often strike in the 3rd through 6th decades of life depending on the tumor's site of origin. ${ }^{17,53}$ This debilitating tumor often causes loss of neurological function in individuals who would otherwise be highly productive. Furthermore, the SEER database indicates a median diagnosis age of 58.5 years (range 3-95 years) and a median survival of 6.29 years from the time of diagnosis, with 5-, 10-, and 20-year survival rates of $47 \%-80 \%, 40 \%$, and $13 \%$, respectively, regardless of race, ethnicity, or sex..$^{17,37,53}$

\section{History of Pathology and Clinical Descriptions}

The story of chordoma begins in 1846 when the prolific
German physician and pathologist Rudolf Virchow (Fig. 1) noted on autopsy an incidental, small, slimy growth on the surface of the clivus blumenbachii (dorsum sellae). ${ }^{4}$ In 1856, during a routine postmortem autopsy, the German anatomist Hubert von Luschka coincidentally stumbled upon a similar soft, transparent, lobulated mass that entered the cranial cavity at the sella turcica. ${ }^{6,27,31}$ Perplexed by this finding, Virchow conducted a histological investigation, and within a year of von Luschka's observations, Virchow became the first to fully describe and name this peculiar tumor. In 1857, Virchow coined the term "chordomata," and in his description, he noted its interesting embryonic character and referred to it as an "ecchondrosis physalifora spheno-occipitalis," which directly translates to a "cartilaginous physaliphorous" lesion of the cartilaginous junction between the basisphenoid and basiocciptal bones. ${ }^{27,31,45} \mathrm{He}$ essentially believed that chordomata was a cartilaginous neoplasm caused by softening of the cartilage matrix and degradation of surrounding tissues, which leads to excess water accumulation and vesicular transformation of the cells., ${ }^{6,27,31} \mathrm{He}$ used the word "physaliphora" (physaliphorous) in reference to the many cytoplasmic vacuoles seen on microscopic examination. This is a pathognomonic feature of chordoma to this day (Fig. 2). ${ }^{20}$

In 1858, Virchow's doctoral advisor, German anato-

ABBREVIATIONS SEER = Surveillance, Epidemiology, and End Results.

SUBMITTED June 15, 2017. ACCEPTED July 28, 2017.

INCLUDE WHEN CITING Published online February 2, 2018; DOI: 10.3171/2017.7.SPINE17668. 


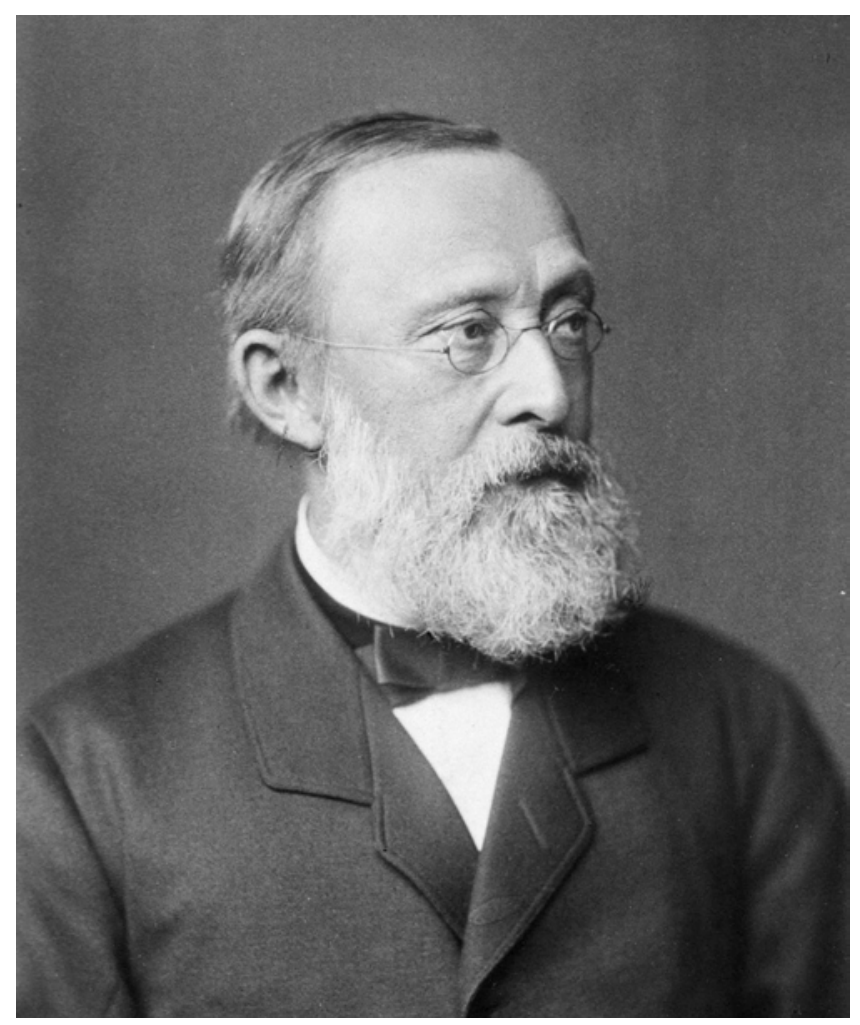

FIG. 1. Photograph of Rudolf Virchow in 1885. Image from https:// commons.wikimedia.org/wiki/File:Rudolf_Virchow_NLM4.jpg. Public domain.

mist Johannes Peter Müller, postulated that chordomata may originate from notochordal tissue. Müller's hypothesis was based on the fact that most vertebrates, including humans, contain remnants of notochordal tissue in the basilar cartilage, sacrum, and spheno-occipital synchondrosis (analogous to the nucleus pulposus of intervertebral discs). ${ }^{27}$ Unfortunately, Müller did not have sufficient evidence at the time to verify his beliefs; thus, Virchow, Luschka, and other peers rejected his theory. ${ }^{27}$

Müller's hypothesis became the subject of dispute and inspired concentrated interest on describing the pathological development and characteristics of chordomata, specifically with regard to the development of the notochord, especially among Virchow, von Luschka, Kölliker, Löwe, Fric, and Heiberg. ${ }^{31}$ Virchow's view, that chordomata derives from cartilage and not notochord, became almost universally accepted in 1880 after the Belgian physician and anatomist Hector Leboucq noted that notochordal tissue is destroyed before birth in human embryos and that intervertebral notochordal expansion is replaced by connective tissue. ${ }^{55}$ Although incorrect and contradictory to many published works of the time, this conclusion was widely accepted and influenced others to believe in Virchow's initial postulation; some, however, remained skeptical and continued further research into the matter..$^{55}$

After 36 years of debate over Müller's notochordal hypothesis, observations by the German pathologist Moritz Wilhelm Hugo Ribbert lent more credibility to the view that chordoma is derived from notochord. In 1894, after

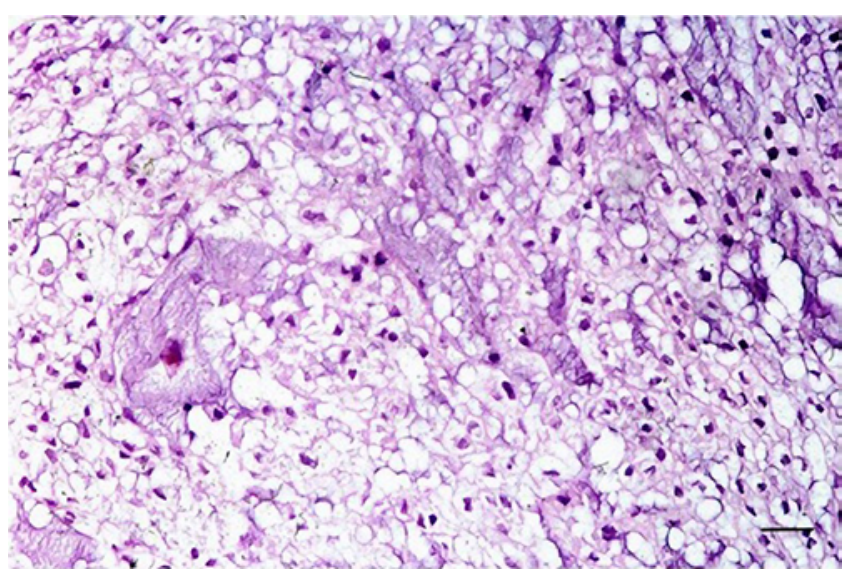

FIG. 2. Light microscopy image of a chordoma demonstrating islands/ cords of eosinophilic and vacuolated cells within a basophilic myxoid stroma. $\mathrm{H} \& \mathrm{E}$. Bar $=70 \mu \mathrm{m}$. From Dalprà et al: First cytogenetic study of a recurrent familial chordoma of the clivus. Int J Cancer 81:24-30, 1999. Published with permission. Figure is available in color online only.

reviewing 5 cases of clival chordomata, Ribbert proposed a set of arguments supporting acceptance of Müller's view. ${ }^{6,27,31,45}$ He first argued that all observed cases of chordomata had originated from the midline of the clivus. He then asserted that no case of chordomata had presented as a transition from cartilage to cancerous tissue; thus, these tumors merely coexisted as intracartilaginous notochordal vestiges. Furthermore, he pointed out that in a cartilaginous tumor, one does not observe a gelatinous texture coincident with a physaliphorous appearance. ${ }^{21,36}$ Later that same year, Ribbert conducted an experiment to further prove the notochordal hypothesis and his adduced reasons. In his 1894 experiment, Ribbert punctured the intervertebral discs of a group of rabbits, which caused herniation of the nucleus pulposus and the proliferation of tissue histologically similar to that of chordomata. On autopsy examination, he found notochordal tissue in the clivus of approximately $2 \%$ of the rabbit corpses. ${ }^{6,21,27,31,36,45}$

In the meantime, the intense focus on a pathological description caused no real clinical description to be noted. ${ }^{31}$ The first-ever symptomatic description of a patient with spheno-occipital chordomata was given in 1864 by Arnold C. Klebs, a Swiss physician. ${ }^{31,45}$ Klebs later reported on the first case of cervical vertebrae chordomata in 1889 , a patient who died due to increased medullary pressure, which at the time he did not attribute to malignancy of the tumor. ${ }^{14}$

Lothar Henning, a German physician, described the first-ever sacrococcygeal chordomata in a 7-month-old neonate in 1900, but because the patient was very young, her case was considered an anomaly. ${ }^{27}$ In 1904, Ribbert conducted a series of 500 autopsies, in which he identified 10 cases of clival chordomata, an incidence of $2 \%$, which is similar to the incidence he had observed in his rabbit experiment.$^{55}$ Later that year, he proposed the name "chordoma," instead of chordomata, to designate this tumor. ${ }^{55}$

Up to this point, chordomas were mainly thought of as benign, slow-growing tumors. Most physicians did not consider this tumor to cause death, until in 1903, when 
Grahl recorded the first case resulting in death, in which a tumor had caused an increase in intracranial pressure and involved the brainstem. ${ }^{31}$ Grahl's patient, a 51-year-old woman, presented with neurological symptoms, including headaches, deafness, and visual impairment caused by paralysis of the third, fourth, and seventh cranial nerves. Furthermore, she presented with dysarthria and dysphagia and eventually died from paralysis of the medullary centers. ${ }^{8}$ On autopsy, Grahl found a 3-cm tumor in the sella turcica, resembling a chordoma. ${ }^{31}$ Soon thereafter, in 1907, physicians Fischer and Steiner brought attention to the likely clinically malignant nature of chordoma after a 16-year-old boy presented with numerous progressing neurological symptoms, which eventually led to his death. The boy's autopsy exposed a chordoma causing extensive degeneration of the brain via destruction of posterior structures down to the second cervical vertebra. ${ }^{8,31}$

In 1909, the physician Linck presented a case of considerable pathological interest. A middle-aged man had presented with a mass the "size of a pigeon's egg" in his pharynx, resulting in auditory discharge and otitis. ${ }^{8}$ Within a month, 2 operations were performed, and greasy mucoid material, which proved to be chordoma tissue, was obtained. This was the first demonstration of nasopharyngeal chordoma, which prompted Linck to establish a set of histological characteristics to describe and identify chordoma regardless of where it occurs. He noted the formation of intra- and extracellular mucus, lobular and chordal arrangement of physaliferous mucus-containing cells, and similarity of the tumor to notochordal tissue of the nucleus pulposus as key characteristics of chordoma. ${ }^{8}$

In 1910, physicians Feldmann and Mazzia reported the first official case of a sacrococcygeal chordoma in a 46-year-old woman..$^{27,36}$ This patient had a yearlong progressive soft swelling of the sacro-perineal region, which proved to be chordoma tissue. ${ }^{5}$ Soon after, in 1919, Pototschnig recorded the first observed case of metastatic chordoma. His patient presented with a sacrococcygeal chordoma that had recurred after operation and had produced a metastasis to the regional lymph nodes. ${ }^{27,36}$

After publishing a series of papers from 1914 to 1922, physician-scientists Alezais and Peyron presented 3 histological criteria for the development of chordoma, which directly correlate to the classic stages of the evolution of the primitive notochord. ${ }^{5,21}$ First, a hollow tube lined with endodermal tissue arises. Then, this tube is transformed to a solid cord of tightly packed undifferentiated cells (instead of polyhedral epithelial cells typically found in chorda dorsalis). Last, the cells become vacuolated, fibrillate, and produce mucin, which aids in adaptation of a supportive structure. ${ }^{5,21}$

A year later, in 1923, after reviewing various chordoma cases, Stewart and Burrow suggested using the term "ecchordosis physaliphora" (instead of Virchow's initial "ecchondrosis") to classify nonaggressive nests of the notochord without malignant growth potential and "chordoma" (Fig. 3) for the invasive forms of the disease. ${ }^{7,8,21}$ This distinction was crucial, for the word "ecchordosis" acknowledged the chordoma's notochordal origin, as opposed to a cartilaginous origin, and separated the harmless benign form from the true neoplasm (chordoma).,8,21

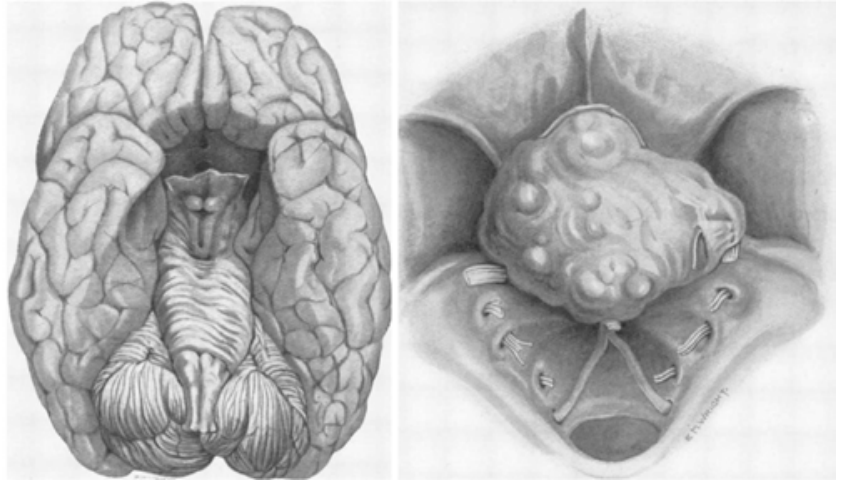

FIG. 3. Malignant spheno-occipital tumor described by Burrow and Stewart. Left: Observe the "deep depression, ... . stretching, flattening and distortion of the pons, crura cerebri, optic tracts and chiasma" caused by the invasive tumor. Right: The same tumor localized on dorsum sellae and pituitary fossa. Reproduced from Burrow JLF, Stewart MJ: J Neurol Psychopathol 1:205-217, 1923, with permission from BMJ Publishing Group Ltd.

Stewart and Burrow suggested that the more solid and opaque the tumor was, the less mucous it would produce and the more malignant it would be., 7,21

In the late 1920 s and early 1930s, the first high-quality literature reviews were conducted by Coenen (1925), Corsy and Surmont (1927), and Stewart and Morin (1926). ${ }^{10,12,50}$ These reviews had great impact on the overall understanding of the disease. ${ }^{4}$ In the 1925 review, Coenen, a German surgeon, studied 68 cases of various chordomas and, based on given clinical and embryological descriptions, proposed the first classification for the different forms of chordoma, a table that was used and modified in every paper thereafter.,21 In 1935, Mabrey, an American physician from Boston, Massachusetts, reviewed the first 150 cases of chordoma ever reported and created an elaborate observational report to evaluate this disease and its standard of care. Mabrey's retrospective study used Coenen's classifications and revealed a much higher prevalence of sacrococcygeal and cranial tumors than lesions of the mobile spine..$^{36}$ In addition, he noted an average survival of 17.5 months after symptom onset, a higher incidence of disease in men, increased survival after resection in sacrococcygeal cases, and a lack of characteristic symptoms for any form of the disease.

Furthermore, Mabrey observed symptoms unique to various types of chordoma. He reported that cranial chordoma is often accompanied by a dull and rarely neurological headache, as opposed to vertebral chordoma, which commonly presents with sharp pain with radiculopathy, and sacrococcygeal chordoma, which often presents with dull yet prominent pain. Cranial chordoma can also lead to visual disturbance and dizziness. Weakness and paralysis in the lower extremities are commonly seen in vertebral chordomas.

In 1952, pathologist Charles Congdon replicated Ribbert's original rabbit experiment. ${ }^{11}$ By demonstrating nucleus pulposus cell regeneration following intervertebral disc puncture, Congdon confirmed Müller's hypothesis of chordoma's notochordal origin. ${ }^{11}$ In 1973, Heffelfinger and 
colleagues, from the Mayo Clinic in Minnesota, defined the more clinically benign and cartilaginous-like chondroid chordoma variant with neoplastic cells. ${ }^{2,24}$ Six years later, the 4 types of clival tumor extensions were discussed for the first time by Nolte, a pediatric radiologist from Tübingen, Germany. ${ }^{5}$ Of the anterior, posterior, superior, and inferior extensions he defined, Nolte noted that children younger than 5 mainly presented with clival tumors with inferior extensions. ${ }^{5}$

\section{History of Diagnosis}

For the first 80 years of chordoma's history, the only clear way to recognize it was through autopsy or biopsy. Not until 1922 did the physician Micotti use exploratory puncture to correctly diagnose a patient with sacrococcygeal chordoma, and in 1926, another physician, named Adler, used radiographic imaging to correctly diagnose 5 patients with sacrococcygeal chordoma. ${ }^{36}$ The extreme difficulty in diagnosing such tumors was noted by Mabrey, who, in 1935, discussed possible diagnostic tools for various types of chordomas. ${ }^{36}$ In cranial chordoma, diagnosis could potentially be determined via clivus or clinoidal defects seen on radiographic imaging, increased intracranial pressure measurements, or exploratory punctures. ${ }^{36} \mathrm{In}$ vertebral chordoma, vertebral destruction could be seen on radiographs because of the chordoma's nucleus pulposus origin. In addition, long-term pressure from tumor mass effect could lead to xanthochromia and vertebral fracture in patients. ${ }^{36}$ Lastly, sacrococcygeal chordoma could present on radiography with a soft-tissue shadow accompanied by bone destruction. Inspection for enlarged vacuolated cells with homogeneous mucoid substances was the most appropriate initial diagnostic step if sacrococcygeal chordoma was suspected. Unfortunately, only $12 \%$ of these cases were correctly diagnosed at the time of Mabrey's report. ${ }^{36}$

In 1955, Shackelford and Rhode, who focused on sacrococcygeal chordoma, observed that many cases presented with presacral masses that were potentially detectable through digital palpation of the posterior rectum and that the mass mostly did not adhere to the overlying skin. ${ }^{46}$ Moreover, they saw that roentgenological data could reveal radiotranslucency, which suggests sacral destruction or rarefaction. ${ }^{46}$ They concluded that clinicians could confirm diagnoses solely by aspiration biopsy or by intraoperative procurement of the specimen and subsequent frozen section..$^{46}$

The existence of chondroid chordoma, defined by Heffelfinger and mentioned above, was questioned until 1994, when an organographic examination by Ishida and Dorfman, pathologists in the orthopedic surgery department at Albert Einstein College of Medicine, established a classification scheme for this chordoma variant: 1) predominantly chordoid pattern and small chondroid foci, 2) equal volumes of chondroid and chordoid components, and 3) cytokeratin and epithelial membrane antigen positivity.,29 Negative-stained cartilaginous tumors containing chordoid elements became recognized as chondrosarcomas. ${ }^{2,29}$

Another important aspect of chordoma diagnosis deals with chordoma genetics. Our recent understanding of the genetics of chordoma stems from notable familial chordoma patients, starting with Foote and colleagues' discussion of a case involving middle-aged siblings experiencing familial sacrococcygeal chordomas, which paved the way for other discussions on familial cases..$^{22}$ Despite reports of congenital chordomas, the youngest reported patient with a positive family history was 3 years old. ${ }^{22}$ Cytogenetic examinations of 2 daughters and their father suspected of familial chordoma showed karyotypic heterogenic hypo- or diploidy. ${ }^{22}$ Furthermore, fluorescence in situ hybridization showed dic(1;9)(p36.1;p21) clonal and nonclonal chromosomal rearrangements, with notable unbalanced translocation in chromosome $1 \mathrm{p}^{22}$ Since the genetics of chordoma is technical and beyond the scope of this historical paper, we recommend further reading regarding the genetics and biological basis of chordoma. ${ }^{22,33}$

\section{History of Surgical Treatment}

In 1919, Daland, a physician at the Massachusetts General Hospital, operated on the first spheno-occipital case. ${ }^{36}$ A woman, age 30, who had endured symptoms for 3 years, presented with a tumor extending from the region of the right ear into the neck. There was a bulging into the right auditory canal, as well as decreased sensation and atrophy of the right side of the tongue. The tumor in the neck was curetted, and its connection with the base of the skull was established. Recurrence took place despite radiation therapy; however, the patient was alive at the time the case was published. ${ }^{8,14,21,36}$

In a 1923 case report, Hirsch described an operation on a nasopharyngeal chordoma via splitting the palate; the tumor recurred 1 year later.,27 In 1928, Argaud and Clermont reported on the transsinuso-facial removal of a 48-year-old woman's nasopharynx chordoma; the tumor returned months later. ${ }^{4}$ During the same year, Loebell described a surgical antrum approach and radium treatment of a left nasopharynx chordoma in a 62-year-old man experiencing vertigo and symptoms in the left ear and left nostril, who also demonstrated radiographic defects in the petrous bone and sella turcica. ${ }^{4}$ The tumor returned 1.5 years later, followed by death. ${ }^{4}$

In a 1955 review focused on sacrococcygeal chordoma, Shackelford and Rhode reported that the earliest tumor excisions, often performed with piecemeal removal via local curettage, resulted in boney remnants leading to tumor recurrence. ${ }^{46}$ Surgical treatments later advanced to anteriorly or posteriorly approached en bloc excisions of sacrum, coccyx, and chordoma, while sparing the rectum. ${ }^{40}$ The sacral bone was transected at subjectively safe levels above the chordoma's extraosseous base. ${ }^{46}$

In a 1960 publication by Hungarian neurosurgeons Zoltan and Fenyes, records of various initial operations to treat cranial chordomas were noted. According to these authors, the first transnasal operation occurred in 1911, the first craniotomy in 1918, and the first suboccipital craniotomy and decompression in 1923..$^{59}$ They also noted that the first resection through the upper jaw or palate occurred in 1923, the first transfrontal exposure through ethmoidal cells in 1929, and the first cerebellar craniotomy, transfrontal craniotomy, and transsphenoidal resection in 1941, 
1941, and 1953, respectively. ${ }^{59}$ In 1966, neurosurgeons at the University of California, San Francisco, described a transcervical transclival approach for resection of a clivus chordoma; they postulated that a transcervical approach would help to prevent hemorrhage and meningeal infection. ${ }^{49}$

\section{History of Radiotherapy}

In 1919, Porter and Daland tested out "two massive x-ray treatments" on their patient; however, the efficacy of radiation was not yet known. ${ }^{14}$ In 1955, Shackelford reported radiotherapy to be ineffective on its own, with only potential pain relief in inoperable patients. He reported a maximum 5-year survival rate following radiotherapy alone and noted that its addition to surgery was never seen to prevent tumor recurrence. ${ }^{46}$

In 1964, researchers demonstrated that radiation dosages above $5000 \mathrm{rad}$ prolonged remission. Three years later, Higinbotham, an American pathologist at Memorial Sloan Kettering, showed that a minimum 7000-rad dosage was needed for beneficial results. ${ }^{25,38}$ In 1970, Pearlman and Friedman, from New York University Hospital's Department of Radiation Therapy, assessed the photon radiation therapy dosage in tumor control and reported an $80 \%$ success rate with $80 \mathrm{~Gy}$ of radiation as opposed to a $20 \%$ success rate in the 40- to 60 -Gy radiation groups. ${ }^{2,43}$ In 1986, Dr. Amendola reported that radiotherapy was most effective if administered postresection., ${ }^{2,43}$

Proton beam therapy is an alternative to conventional radiotherapy, especially when tumors are located in sensitive or critical locations, namely skull base chordomas. ${ }^{34}$ This charged-particle therapy provides an excellent and conformal dose distribution with no exit dose. ${ }^{34}$ In 1982, Suit et al., from the Massachusetts General Hospital, used proton beam radiotherapy in 10 chordoma and sarcoma patients and described local control with no complications in any of the patients. ${ }^{51}$ Proton beam therapy remains an active field of research but is beyond the scope of this review; however, excellent papers covering proton beam therapy are readily available. ${ }^{3}$ We recommend focused articles and reviews for further information regarding current state-of-the-art radiation therapy and proton beam therapy in treating chordoma. ${ }^{16,44}$

\section{Evolution to Current Treatment}

There have been many developments in the fields of chordoma molecular biology, genetics, and multimodal treatment approaches since the initial characterization of this tumor in 1846. Even in the present day, chordoma remains poorly responsive to conventional chemotherapy and radiotherapy, leaving radical resection as the most common option despite a $26.7 \%-66.7 \%$ recurrence rate and $65 \%$ 5-year survival. ${ }^{30,56,60}$ Given this high rate of recurrence, chordoma treatment has recently focused on prognostic stratification of patients based on neoplasm location (40\% of chordomas occur at the clivus or cervical spine, and $60 \%$ occur at the sacrococcygeal junction of the spine), protein and genetic biomarker expression (for example, brachyury or bone morphogenetic protein 4 [BMP4] expression, or loss of genetic material), epigenetic modifications, and a variety of clinical and demographic criteria (for example, age and sex). ${ }^{18,30,37,41,60}$ Brachyury, for example, is a transcription factor of the T-box family that is a sensitive and specific marker that is readily expressed in chordoma and thought to serve as an important diagnostic and prognostic biomarker. ${ }^{39}$ Other markers, such as sex steroid receptors COX- 2 and ER- $\beta$, have implicated age and sex in the prognostic outcomes of chordoma patients. ${ }^{13}$ This recent work has led to a variety of clinical trials with targets ranging from molecular targets and brachyury to EZH2 (a transcriptional regulator). ${ }^{1,9}$

Multimodal treatment approaches have significantly altered the therapeutic paradigms for chordoma patients over recent decades. In patients with inoperable and progressive disease, imatinib has been shown to arrest tumor growth. ${ }^{26}$ Chemotherapy (for example, imatinib) and radiotherapy (for example, pencil beam scanning proton therapy) combined with resection, as compared with unimodal therapy, have significantly enhanced the 7-year metastasis-free and overall survival rates in patients. ${ }^{54}$ With respect to clival chordomas, multimodal approaches include craniotomy or endoscopic approaches, in an either staged or simultaneous fashion, combined with adjuvant intensity-modulated radiation therapy (IMRT), proton beam therapy, or Gamma Knife surgery.

Even with the current understanding of surgical, radiosurgical, and medical management of chordoma, a significant bulk of the underlying chordoma pathobiology remains unknown, as evidenced by the high rate of recurrence..$^{19,53}$ Active research on tyrosine kinase and STAT3 transcription manipulation, as well as tyrosine kinase inhibitor therapies such as nilotinib and dasatinib, has shown potential. ${ }^{42,47,53,58}$ It has also been reported that Notch and MAPK receptor pathways with their corresponding microRNAs (miRNAs) may play critical roles in chordoma biology. ${ }^{35}$ Furthermore, characterizing the chordoma cell line may facilitate investigations into targeted therapy aimed at arresting tumor growth. ${ }^{28,53,57}$ Carbon ion radiation therapy has been shown to be effective in treating skull base chordoma. ${ }^{52}$ Gamma Knife surgery to treat skull base chordoma is an active field of interest, and we recommend additional reading regarding its qualifications and outcomes. ${ }^{15,23} \mathrm{~A}$ review by Kayani et al. concluded that wide-margin resection offers the best prognosis for sacral chordoma; however, further investigation into the exact benefits of radiotherapy for patients with inadequate operative margins is warranted. ${ }^{32}$ The significant heterogeneity and rarity of chordoma makes it difficult to conduct randomized trials to assess differences among surgery, radiosurgery, and combinatorial therapy. ${ }^{48}$ Lastly, we recommend implementing new therapeutic evaluation metrics for chordoma, with a focus on quality of life outcomes, growth modulation index, change in contrast and PET response, and the tumor's degree of circulating DNA.48

In Figure 4, we provide a historical timeline summarizing the foundational discoveries and pioneering therapeutic events concerning chordoma.

\section{Conclusions}

The recognition and treatment of chordoma as a histo- 


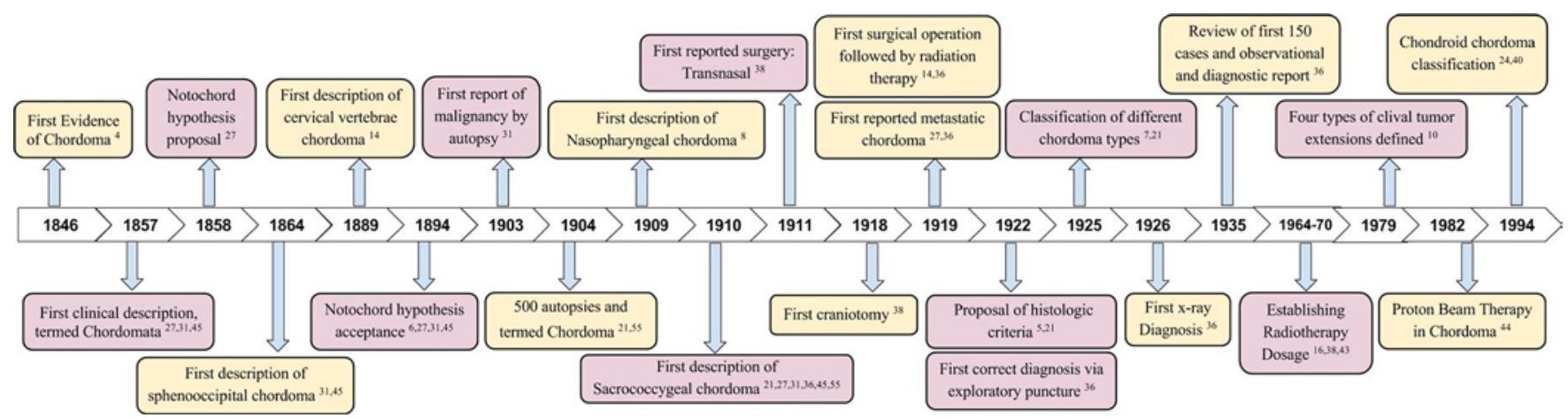

FIG. 4. Historical timeline of the fundamental discoveries and pioneering therapeutic milestones. Figure is available in color online only.

logically benign tumor with malignant pathophysiological manifestation has greatly evolved over the past 170 years. The initial discovery came from Virchow with contributions from Luschka and Müller, with the latter correctly hypothesizing that chordoma had a notochord origin. Thereafter, a multitude of autopsy and case studies led to initial classifications and diagnostic guidelines that established chordoma's malignancy, contrary to prior beliefs. Both surgical and radiation therapies to treat chordoma were initiated by Daland's tumor curette operation, followed by x-ray radiation. A series of initially reported cases of various forms of chordoma, such as spheno-occipital, vertebral, sacrococcygeal, nasopharyngeal, and metastatic chordoma, led to a better understanding of diagnosis and treatment.

\section{Acknowledgments}

Mr. Sahyouni is funded in part by a Medical Scientist Training Program grant from the NIH (T32-GM08620).

\section{References}

1. Agulnik M, Tannir NM, Pressey JG, Gounder MM, Cote GM, Roche M, et al: A phase II, multicenter study of the EZH2 inhibitor tazemetostat in adult subjects with INI1-negative tumors or relapsed/refractory synovial sarcoma. J Clin Oncol 34 (15 Suppl):TPS11071, 2016 (Abstract)

2. al-Mefty O, Borba LA: Skull base chordomas: a management challenge. J Neurosurg 86:182-189, 1997

3. Allen AM, Pawlicki T, Dong L, Fourkal E, Buyyounouski M, Cengel K, et al: An evidence based review of proton beam therapy: the report of ASTRO's emerging technology committee. Radiother Oncol 103:8-11, 2012

4. Bailey P, Bagdasar D: Intracranial chordoblastoma. Am J Pathol 5:439-450, 1929

5. Beccaria K, Puget S, George B, Sainte-Rose C: Chordomas and their management, in Özek MM, Cinalli G, Maixner W, et al (eds): Posterior Fossa Tumors in Children. Cham: Springer, 2015, pp 703-720

6. Beccaria K, Sainte-Rose C, Zerah M, Puget S: Paediatric Chordomas. Orphanet J Rare Dis 10:116, 2015

7. Borba LA, Colli BO, Al-Mefty O: Skull base chordomas. Neurosurg Q 11:124-139, 2001

8. Burrow JLF, Stewart MJ: Malignant spheno-occipital chordoma. J Neurol Psychopathol 4:205-217, 1923

9. Chi SN, McCowage GB, Hoffman L, Macy M, Doleman S, Blakemore SJ, et al: A phase I study of the EZH2 inhibitor tazemetostat in pediatric subjects with relapsed or refractory
INI1-negative tumors or synovial sarcoma. J Clin Oncol 34 (15 Suppl):TPS10587, 2016 (Abstract)

10. Coenen H: Das Chordom. Beitr Klin Chir 133:1, 1925

11. Congdon CC: Proliferative lesions resembling chordoma following puncture of the nucleus pulposus in rabbits. J Natl Cancer Inst 12:893-907, 1952

12. Corsy F, Surmont J: Sur l'histogénèse, l'évolution des tumeurs de la notochorde. Bull Assoc Fr Etud Cancer 16:316-376, 1927

13. Curtis KM, Young VA, Temple HT, Eismont FJ, DeLaney TF, Hornicek FJ: Characteristics and patterns of metastatic disease from chordoma, presented at the Endocrine Society 98th Annual Meeting. Metastasis and Tumor Progression, Neoplasia of Endocrine Tissue, Therapies for Cancer, and Tumorigenesis, Boston, 2016 (Poster) (http:// press.endocrine.org/doi/abs/10.1210/endo-meetings.2016. TB.7.SUN-078) [Accessed September 27, 2017]

14. Daland EM: Chordoma. Boston Med Surg J 180:571-576, 1919

15. Dassoulas K, Schlesinger D, Yen CP, Sheehan J: The role of Gamma Knife surgery in the treatment of skull base chordomas. J Neurooncol 94:243-248, 2009

16. De Amorim Bernstein K, DeLaney T: Chordomas and chondrosarcomas - the role of radiation therapy. J Surg Oncol 114:564-569, 2016

17. Diaz RJ, Cusimano MD: The biological basis for modern treatment of chordoma. J Neurooncol 104:411-422, 2011

18. Eriksson B, Gunterberg B, Kindblom LG: Chordoma. A clinicopathologic and prognostic study of a Swedish national series. Acta Orthop Scand 52:49-58, 1981

19. Fagundes MA, Hug EB, Liebsch NJ, Daly W, Efird J, Munzenrider JE: Radiation therapy for chordomas of the base of skull and cervical spine: patterns of failure and outcome after relapse. Int J Radiat Oncol Biol Phys 33:579-584, 1995

20. Fernandez-Miranda JC, Gardner PA, Snyderman CH, Devaney KO, Mendenhall WM, Suárez C, et al: Clival chordomas: a pathological, surgical, and radiotherapeutic review. Head Neck 36:892-906, 2014

21. Firooznia H, Pinto RS, Lin JP, Baruch HH, Zausner J: Chordoma: radiologic evaluation of 20 cases. AJR Am J Roentgenol 127:797-805, 1976

22. Güdük M, Özek MM: Molecular biology and genetics of chordomas, in Özek MM, Cinalli G, Maixner W, et al (eds): Posterior Fossa Tumors in Children. Cham: Springer, 2015, pp 675-682

23. Hasegawa T, Ishii D, Kida Y, Yoshimoto M, Koike J, Iizuka $\mathrm{H}$ : Gamma Knife surgery for skull base chordomas and chondrosarcomas. J Neurosurg 107:752-757, 2007

24. Heffelfinger MJ, Dahlin DC, MacCarty CS, Beabout JW: Chordomas and cartilaginous tumors at the skull base. Cancer 32:410-420, 1973 
25. Higinbotham NL, Phillips RF, Farr HW, Hustu HO: Chordoma. Thirty-five-year study at memorial hospital. Cancer 20:1841-1850, 1967

26. Hindi N, Casali PG, Morosi C, Messina A, Palassini E, Pilotti S, et al: Imatinib in advanced chordoma: A retrospective case series analysis. Eur J Cancer 51:2609-2614, 2015

27. Hirsch EF, Ingals M: Sacrococcygeal chordoma. J Am Med Assoc 80:1369-1370, 1923

28. Hsu W, Mohyeldin A, Shah SR, ap Rhys CM, Johnson LF, Sedora-Roman NI, et al: Generation of chordoma cell line JHC7 and the identification of Brachyury as a novel molecular target. J Neurosurg 115:760-769, 2011

29. Ishida T, Dorfman HD: Chondroid chordoma versus lowgrade chondrosarcoma of the base of the skull: can immunohistochemistry resolve the controversy? J Neurooncol 18:199-206, 1994

30. Jahangiri A, Chin AT, Wagner JR, Kunwar S, Ames C, Chou $\mathrm{D}$, et al: Factors predicting recurrence after resection of clival chordoma using variable surgical approaches and radiation modalities. Neurosurgery 76:179-186, 2015

31. Jelliffe SE, Larkin JH: Malignant chordoma involving brain and spinal cord. J Nerv Ment Dis 39:1-16, 1912

32. Kayani B, Hanna SA, Sewell MD, Saifuddin A, Molloy S, Briggs TW: A review of the surgical management of sacral chordoma. Eur J Surg Oncol 40:1412-1420, 2014

33. Kitamura Y, Sasaki H, Yoshida K: Genetic aberrations and molecular biology of skull base chordoma and chondrosarcoma. Brain Tumor Pathol 34:78-90, 2017

34. Levin WP, Kooy H, Loeffler JS, DeLaney TF: Proton beam therapy. Br J Cancer 93:849-854, 2005

35. Long C, Jiang L, Wei F, Ma C, Zhou H, Yang S, et al: Integrated miRNA-mRNA analysis revealing the potential roles of miRNAs in chordomas. PLoS One 8:e66676, 2013

36. Mabrey RE: Chordoma: a study of 150 cases. Am J Cancer 25:501-517, 1935

37. McMaster ML, Goldstein AM, Bromley CM, Ishibe N, Parry DM: Chordoma: incidence and survival patterns in the United States, 1973-1995. Cancer Causes Control 12:1-11, 2001

38. McSweeney AJ, Sholl PR: Metastatic chordoma use of mechlorethamine (nitrogen mustard) in chordoma therapy. AMA Arch Surg 79:152-155, 1959

39. Miettinen M, Wang Z, Lasota J, Heery C, Schlom J, Palena $\mathrm{C}$ : Nuclear brachyury expression is consistent in chordoma, common in germ cell tumors and small cell carcinomas, and rare in other carcinomas and sarcomas. An immunohistochemical study of 5229 cases. Am J Surg Pathol 39:13051312,2015

40. Mixter CG, Mixter WJ: Surgical management of sacrococcygeal and vertebral chordoma. Arch Surg 41:408-421, 1940

41. Moussazadeh N, Berman SH, Laufer I, Gounder M, Zheng Y, Sommer J, et al: Epigenetic profiling reveals a unique histone code in chordoma. Neurosurgery 63 (Suppl 1):208, 2016 (Abstract)

42. Negri T, Casieri P, Miselli F, Orsenigo M, Piacenza C, Stacchiotti S, et al: Evidence for PDGFRA, PDGFRB and KIT deregulation in an NSCLC patient. Br J Cancer 96:180-181, 2007

43. Pearlman AW, Friedman M: Radical radiation therapy of chordoma. Am J Roentgenol Radium Ther Nucl Med 108:333-341, 1970

44. Pennicooke B, Laufer I, Sahgal A, Varga PP, Gokaslan ZL, Bilsky MH, et al: Safety and local control of radiation therapy for chordoma of the spine and sacrum: a systematic review. Spine (Phila Pa 1976) 41 (Suppl 20):S186-S192, 2016

45. Raghavan D, Ahluwalia MS, Blanke CD, Brown J, Kim ES, Reaman GH, et al: Textbook of Uncommon Cancer. Hoboken: Wiley, 2017

46. Shackelford RT, Rhode CM: Sacrococcygeal chordoma; its surgical treatment. Ann Surg 141:952-966, 1955
47. Stacchiotti S, Casali PG: Systemic therapy options for unresectable and metastatic chordomas. Curr Oncol Rep 13:323-330, 2011

48. Stacchiotti S, Sommer J: Building a global consensus approach to chordoma: a position paper from the medical and patient community. Lancet Oncol 16:e71-e83, 2015

49. Stevenson GC, Stoney RJ, Perkins RK, Adams JE: A transcervical transclival approach to the ventral surface of the brain stem for removal of a clivus chordoma. J Neurosurg 24:544-551, 1966

50. Stewart MJ, Morin JE: Chordoma: a review, with report of a new sacrococcygeal case. J Pathol Bacteriol 29:41-60, 1926

51. Suit HD, Goitein M, Munzenrider J, Verhey L, Davis KR, Koehler A, et al: Definitive radiation therapy for chordoma and chondrosarcoma of base of skull and cervical spine. $\mathbf{J}$ Neurosurg 56:377-385, 1982

52. Uhl M, Mattke M, Welzel T, Roeder F, Oelmann J, Habl G, et al: Highly effective treatment of skull base chordoma with carbon ion irradiation using a raster scan technique in 155 patients: first long-term results. Cancer 120:3410-3417, 2014

53. Walcott BP, Nahed BV, Mohyeldin A, Coumans JV, Kahle KT, Ferreira MJ: Chordoma: current concepts, management, and future directions. Lancet Oncol 13:e69-e76, 2012

54. Weber DC, Malyapa R, Albertini F, Bolsi A, Kliebsch U, Walser M, et al: Long term outcomes of patients with skullbase low-grade chondrosarcoma and chordoma patients treated with pencil beam scanning proton therapy. Radiother Oncol 120:169-174, 2016

55. Williams LW: The later development of the notochord in mammals. Am J Anat 8:251-284, 1908

56. Yakkioui Y, van Overbeeke JJ, Santegoeds R, van Engeland M, Temel Y: Chordoma: the entity. Biochimica et Biophysica Acta 1846:655-669, 2014

57. Yang C, Hornicek FJ, Wood KB, Schwab JH, Choy E, Iafrate $\mathrm{J}$, et al: Characterization and analysis of human chordoma cell lines. Spine (Phila Pa 1976) 35:1257-1264, 2010

58. Yang C, Schwab JH, Schoenfeld AJ, Hornicek FJ, Wood KB, Nielsen GP, et al: A novel target for treatment of chordoma: signal transducers and activators of transcription 3. Mol Cancer Ther 8:2597-2605, 2009

59. Zoltan L, Fenyes I: Stereotactic diagnosis and radioactive treatment in a case of spheno-occipital chordoma. J Neurosurg 17:888-900, 1960

60. Zou MX, Lv GH, Wang XB, Li J: Factors predicting recurrence after resection of clival chordoma using variable surgical approaches and radiation modalities. Neurosurgery 81(2):E28-E31, 2017 (Letter)

\section{Disclosures}

The authors report no conflict of interest concerning the materials or methods used in this study or the findings specified in this paper.

\section{Author Contributions}

Conception and design: Chen, Sahyouni. Acquisition of data: Sahyouni, Goshtasbi, Mahmoodi. Analysis and interpretation of data: all authors. Drafting the article: all authors. Critically revising the article: all authors. Reviewed submitted version of manuscript: all authors. Approved the final version of the manuscript on behalf of all authors: Chen. Study supervision: Chen, Sahyouni.

\section{Correspondence}

Jefferson W. Chen: UC Irvine Medical Center, Orange, CA. jeffewc1@uci.edu. 